\title{
Oddziaływania tyflomuzykoterapeutyczne wspierające rozwój ruchowy dziecka z niepełnosprawnością wzroku
}

\begin{abstract}
Paweł Cylulko, Oddziatywania tyflomuzykoterapeutyczne wspierające rozwój ruchowy dziecka z niepetnosprawnościa wzroku [Typhlo music therapy interventions that facilitate motor development of visually impaired children]. Interdyscyplinarne Konteksty Pedagogiki Specjalnej, nr 22, Poznań 2018. Pp. 153-30. Adam Mickiewicz University Press. ISSN 2300-391X. DOI: https:/ / doi.org/10.14746/ikps.2018.22.09

The article discusses the possibilities of using music therapy to facilitate motor development of children with visual impairments. Cognitive functioning of children without vision implies certain psychophysiological, emotional and social problems, including substantial delay in motor development in comparison to non-impaired peers. Thanks to the integration of music with various forms of movement and the sonic and musical interaction between a music therapist and a child, it is possible to reduce the child's psychomotor delay, and improve their orientation and locomotion in small and large spaces. The author, musician, teacher and music therapist, shares his observations and experiences gained during almost thirty years of work with children at the Maria Grzegorzewska Lower Silesian Special Educational Centre No. 13 for the Blind and the Visually Impaired in Wrocław.
\end{abstract}

KEY WORDS: visually impaired child, music therapy, rehabilitation, motor development, typhlo music therapy 


\section{Wprowadzenie}

Osoby z niepełnosprawnością wzroku stanowią złożoną i zróżnicowaną pod względem defektu wzroku populację․ Mimo to, można w niej wyróżnić dwie zasadnicze grupy dzieci: niewidome i słabowidzące. Pierwsze pozyskują informacje, orientują się w przestrzeni fizycznej i społecznej, poruszają, komunikują się, uczą i wypoczywają w sposób bezwzrokowy, posługując się głównie dotykiem i słuchem, w dalszej kolejności także węchem oraz smakiem. Natomiast słabowidzące dzieci posiłkują się w tych czynnościach przede wszystkim zachowanymi możliwościami wzrokowymi, ale także w mniejszym stopniu pozostałymi zmysłami. Taki sposób funkcjonowania poznawczego implikuje w ich życiu występowanie swoistych zagadnień psychofizjologicznych, emocjonalnych i społecznych ${ }^{2}$. Można do nich zaliczyć opóźniony w dużym stopniu rozwój ruchowy względem rozwoju pełnosprawnych rówieśników 3 .

Różni specjaliści twierdzą, iż każde dziecko od pierwszych chwil życia przejawia duże zainteresowanie muzyką, a jego muzykalność jest wrodzona4. W przypadku dziecka z niepełnosprawnością wzroku ten rodzaj sztuki nabiera jeszcze większego znaczenia. Dzięki dźwiękowej naturze jest ona dla niego najbliższą, najprzystępniejszą i najbardziej komunikatywną. Jej percepcja może odby-

${ }^{1}$ Z. Palak, Uczniowie niewidomi stabowidzący w szkołach ogólnodostępnych, Wydawnictwo UMCS, Lublin 2000, s. 10-11.

2 A.I. Miedziak, T. Perski, P.P. Andrews, L.A. Donoso, Stargardt's macular dystrophy - a patient's perspective, „Optometry” 2000, nr 71(3), s. 165-176; G.M. Preisler, A descriptive study of blind children in nurseries with sighted children, "Child: care, health and development" 1993, nr 19(5), s. 295-315; H. Tröster, M. Brambring, Early motor development in blind infants, "Journal of applied developmental psychology" 1993, nr 14(1), s. 83-106.

${ }^{3}$ O. Levtzion-Korach, A. Tennenbaum, R. Schnitzer, A. Ornoy, Early motor development of blind children, "Journal of paediatrics and child health" 2000, nr 36(3), s. 226-229.

4 S.N. Malloch, Mothers and infants and communicative musicality, „Musicae scientiae" 1993, nr 1_suppl, s. 29-57. 
wać się w sposób bezpośredni, tj. bez angażowania wzroku, dotyku, węchu i smaku. Słuchając, odtwarzając lub tworząc muzykę, niewidome lub słabowidzące dziecko nie doznaje utrudnień i ograniczeń. Dzięki temu może ono na równi rywalizować z pełnosprawnymi rówieśnikami, a nawet $\mathrm{w}$ niektórych sytuacjach osiągać lepsze rezultaty na jej polu 5 .

We współczesnym społeczeństwie funkcjonuje stereotyp niewidomego, głoszący, iż 1) każde niewidomy posiada ponadprzeciętne zdolności muzyczne, głównie absolutny słuch, szczególne poczucie rytmu, wybitną pamięć muzyczną; 2) zdolności muzyczne są rekompensatą "kalectwa” i idą w parze z jego „ułomnością"; 3) w przyszłości każde dziecko będzie wybitnym muzykiem, który zrobi artystyczną karierę . Takie podejście już na samym początku pracy $z$ dzieckiem stawia je w niewłaściwym świetle, niesłusznie przypisując mu nadzwyczajne zdolności muzyczne. Może ono wówczas odczuwać z jednej strony presję specjalisty, grupy rówieśniczej lub rodziny, z drugiej zaś, rozczarowanie nie mogąc sprostać stawianym przed nim muzycznym wyzwaniom. Jeżeli takie błędne przekonanie będzie lansowane, to wówczas oddziaływania edukacyjne, rehabilitacyjne i terapeutyczne z wykorzystaniem sztuki muzycznej nie przyniosą pokładanych w nich oczekiwań. Aby uniknąć tego typu niebezpiecznych pułapek, wystarczyłoby pamiętać o kompensacyjnej roli analizatora słuchowego dziecka, jego lepszym wyćwiczeniu w różnych sytuacjach akustycznych oraz o tym, iż defek-

${ }^{5}$ M. Antović, A. Bennett, M. Turner, Running in circles or moving along lines: Conceptualization of musical elements in sighted and blind children, "Musicae scientiae" 2013, nr 17(2), s. 229-245; A.A. Darrow, J. Novak, The effect of vision and hearing loss on listeners' perception of referential meaning in music, "Journal of Music Therapy" 2007, nr 44, s. 57-73; Z. Eitan, E. Ornoy, R.Y. Granot, Listening in the dark: Congenital and early blindness and cross-domain mappings in music, "Psychomusicology" 2012, nr 22(1), s. 33; P.J. Flowers, C.H. Wang, Matching verbal description to music excerpt: The use of language by blind and sighted children, "Journal of Research in Music Education" 2002, nr 50(3), s. 202-214.

6 X. Pfammatter, Music as a Leisure-Time Occupation for the Blind, "Review of the European Blind" 1988, nr 2(60), s. 28. 
towi wzroku może także towarzyszyć jego uszkodzenie, które w dużym stopniu determinuje nie tylko jego muzyczną aktywność, ale także funkcjonowanie w innych obszarach życia7.

\section{Charakterystyka rozwoju ruchowego dziecka z niepełnosprawnością wzroku}

Dziecko z niepełnosprawnością wzroku ma taką samą potrzebę ruchu jak jego pełnosprawni rówieśnicy. Jednak nie zawsze jest ona zaspakajana w wystarczającym stopniu i zakresie. Dzieje się tak, gdyż wolniej i później opanowuje ono nowe sprawności ruchowe, trudniej wykonuje czynności samoobsługowe i gospodarcze. Daje się także zauważyć u niego skłonność do bezczynności, co jeszcze bardziej przyczynia się do bierności i ograniczenia ruchliwości ${ }^{8}$. Z uwagi na słabiej rozwinięty aparat mięśniowo-szkieletowy często spotyka się u dziecka zniekształcenia kręgosłupa określane jako wady postawy ciała mające także wpływ na jego sprawność ruchową ${ }^{9}$ Dochodzić mogą do tego również traumatyczne doświadczenia wyniesione z samodzielnego wykonywania ruchów, ćwiczeń fizycznych, zabaw sprawnościowych, pokonywania przeszkód i przemieszczania się $\mathrm{w}$ przestrzeni ${ }^{10}$. Na skutek urazów mechanicznych może rodzić się u dziecka postawa lękowa, pośrednio

${ }^{7}$ A. Okupińska, Zagadnienia rehabilitacji i edukacji osób głuchoniewidomych, [w:] Dajmy szanse niewidomym i stabowidzacym. Poradnik metodyczny dla nauczycieli, red. T. Żółkowska, „Pedagogium” Wydawnictwo OR TWP w Szczecinie, Szczecin 2010, s. 58 .

${ }^{8}$ E. Dziedzic-Szeszuła, Wprowadzenie, [w:] W. Wróblewski, Taniec Towarzyski w rehabilitacji osób niewidomych, AWF, Poznań 2005, s. 10-11.

${ }^{9}$ R. Wypart, Praca nauczyciela wychowania fizycznego z uczniem $z$ dysfunkcja wzroku, [w:] Dajmy szansę niewidomym i stabowidzacym. Poradnik metodyczny dla nauczycieli, red. Żółkowska Teresa, „Pedagogium” Wydawnictwo OR TWP w Szczecinie, Szczecin 2010, s. 171.

10 P.S. Haibach, M.O. Wagner, L.J. Lieberman, Determinants of gross motor skill performance in children with visual impairments, "Research in developmental disabilities" 2014, nr 35(10), s. 2577-2584. 
mająca także wpływ na sferę motoryczną. Brak odpowiedniej ilości i intensywności ruchów powoduje dodatkowo u niego ograniczenie wyobraźni czasowo-przestrzenno-ruchowej, co pociąga za sobą wtórne osłabienie ogólnej ruchliwości oraz utratę wiary we własne siły i możliwości sprawczego działania. Najczęściej zaburzonymi komponentami motoryki dziecka są: siła, szybkość ruchów, koordynacja statyczna, koordynacja dynamiczna całego ciała, estetyka, harmonia i płynność ruchów ${ }^{11}$. Z uwagi na duży lub bardzo duży stopień opóźnienia rozwoju ruchowego dziecka z niepełnosprawnością wzroku niektórzy autorzy twierdzą, iż rozwój ten jest specyficzny, gdyż przejawia się nieprawidłowościami w funkcjonowaniu aparatu ruchowego, opóźnieniami manipulacji i lokomocji, większej asymetrii funkcjonalnej (tj. lateralizacji) rąk oraz formowaniu się anormalnych nawyków ruchowych zwanych blindyzmami. W świetle powyższych stwierdzeń jak najbardziej wskazane wydaje się podejmowanie oddziaływań rehabilitacyjno-terapeutycznych mających na celu usprawnianie rozwoju ruchowego dziecka $\mathrm{z}$ niepełnosprawnością wzroku.

\section{Specyfika muzykoterapii dzieci z niepełnosprawnością wzroku}

W literaturze przedmiotu można natrafić na stosunkowo niewielką liczbę prac z zakresu muzykoterapii dzieci z niepełnosprawnością wzroku, przy czym są to prace z pogranicza edukacji muzycznej, rehabilitacji i muzykoterapii. Ich autorzy, najogólniej ujmując, starają się zaprezentować muzykoterapię jako metodę integrującą struktury i strategie muzyczne, wychowawcze i terapeutyczne w celu niwelowania nieprawidłowych zachowań werbalnych, ruchowych i społecznych oraz stymulowania indywidualne-

${ }_{11} \mathrm{M}$. Brambring, Divergent development of gross motor skills in children who are blind or sighted, "Journal of Visual Impairment \& Blindness" 2006, nr 100(10), s. 620-634; F.M. Murphy, M. O'Driscoll, Observations on the Motor Development of Visually Impaired Children Interpretations from Video Recordings, „Physiotherapy” 1989, nr 75(9), s. 505-508. 
go rozwoju, a tym samym podnoszenia jakości życia dzieci12. Tego typu podejście dało impuls na początku lat 90 . XX w. do wyodrębnienia nowej subdyscypliny muzykoterapii określanej mianem tyflomuzykoterapia. Mimo iż od ponad 20 lat stanowi ona jedną z form zajęć rewalidacyjnych realizowanych w placówkach dostępnych dzieciom niewidomym i słabowidzącym, obok przykładowo takich form, jak: terapia zajęciowa, kinezyterapia, hipoterapia, terapia integracji sensorycznej, to jednak nadal jest traktowana jako niestandardowe rozwiązanie usprawniająco-korekcyjne ${ }^{13}$.

Tyflomuzykoterapia jest oddziaływaniem wykorzystującym muzykę oraz inne niemuzyczne zjawiska akustyczne w celu usprawniania, korygowania i kompensowania zaburzonych funkcji osób z niepełnosprawnością wzroku oraz optymalnego przysposobienia ich do aktywnego partycypowania w różnych obszarach i zakresach życia, zwłaszcza społecznego. Jest ona realizowana zgodnie z paradygmatem humanistyczno-podmiotowej koncepcji niepełnosprawności z jednoczesnym zachowaniem równowagi pomiędzy wiedzą teoretyczną a praktycznym doświadczeniem. W tak pojmowanej terapii stosuje się środki oddziaływania (materiał akustyczny, metody i techniki terapeutyczne, rekwizyty, wyposażenie pracowni, scenariusze zajęć oraz program terapeutyczny) dostosowane do bezwzrokowego sposobu pozyskiwania doświadczeń i uczestniczenia dzieci w sesjach terapeutycznych. Dzięki temu zachodzi głównie bezwzrokowa dźwiękowo-muzyczna interakcja pomiędzy terapeutą a dzieckiem (grupą uczestników), przebiegająca na bazie doznań dotykowo-kinestetycznych, słuchowych, węchowych, smakowych

12 R.C. Lam, C. Wang, Integrating Blind and Sighted through Music, "Music Educators Journal" 1982, nr 68(8), s. 44-45; A.L. Steele, C. Crawford, Music Therapy for the Visually Impaired, „Education of the Visually Handicapped” 1982, nr 14(2), s. 56-62; F.M. Wolf, Music Therapy with the Blind, "British Journal of Music Therapy" 1978, nr 9(3), s. 29.

${ }^{13} \mathrm{~J}$. Kędzierska, Planowanie pracy rewalidacyjnej z dziećmi niewidomymi i stabowidzącymi w szkołach ogólnodostępnych, [w:] Dajmy szansę niewidomym i słabowidzącym. Poradnik metodyczny dla nauczycieli, red. T. Żółkowska, "Pedagogium” Wydawnictwo OR TWP w Szczecinie, Szczecin 2010, s. 104-105. 
oraz wzrokowych (u słabowidzących dzieci). Rodząca się w ten sposób relacja terapeuta - dziecko przyjmuje dynamiczny, przyjazny i emocjonalny charakter ${ }^{14}$. To z kolei pozwala wychowankowi na doświadczanie bezpieczeństwa, intymności, wspólnoty i więzi międzyludzkich ${ }^{15}$. Zatem można powiedzieć, iż tyflologiczne podejście do muzykoterapii w zasadniczy sposób odróżnia ją od innych współcześnie stosowanych modeli i podejść postępowania terapeutycznego.

\section{Ruch integrowany z muzyką w oddziaływaniach tyflomuzykoterapeutycznych}

Ruch jest jednym z najważniejszych środków ekspresji dziecka. Niektórzy autorzy twierdzą, iż jest on warunkiem sine qua non jego rehabilitacji i niezależności ${ }^{16}$. Można zaryzykować twierdzenie, iż niemożliwa jest rehabilitacja i terapia niepełnosprawnego dziecka bez doskonalenia jego motoryki, gdyż w bardzo dużym stopniu wyznacza ona jego autonomię, a przez to poczucie podmiotowości i samostanowienia17. Ruchu nie można niczym zastąpić, ani literaturą, ani plastyką czy filmem, a nawet muzyką. Jest on zjawiskiem trudniej przystępnym dziecku z uszkodzonym analizatorem wzrokowym niż muzyka, przy czym jest on niezbędny dla właściwego jego wzrastania ${ }^{18}$. Najczęściej rodzi się on spontanicznie, z potrzeby

${ }^{14}$ M. Pavlicevic, Dynamie interplay in clinical improvisation, "The Journal of British Music Therapy" 1990, t. 4, nr 2, s. 5-9.

${ }^{15} \mathrm{~K}$. Sobey, Out of sight - out of mind?, Reflections on a blind young woman's use of music therapy, "The Journal of British Music Therapy" 1999, t. 7, nr. 2, s. 8; H.H. Decker-Voigt, Musiktherapeutische Hilfen für die Begleitung von Blinder und Schbenhinderten, „Musiktherapeutische Umschau” 1994, t. 15, nr 2, s. 140-141.

${ }_{16} \mathrm{R}$. Emery, Blind role models in rehabilitation, "Journal of Visual Impairment and Blindness" 1986, nr 80(9), s. 934.

${ }^{17}$ M. Metell, "A great moment... because of the music": An exploratory study on music therapy and early interaction with children with visual impairment and their sighted caregivers, „British Journal of Visual Impairment” 2015, nr 33(2), s. 111-125.

${ }_{18} \mathrm{~J}$. Stadnicka, Rewalidacja dzieci niewidomych przez rytmike, "Szkoła Specjalna” 1990, nr 2-3, s. 76. 
wyrażania przez dziecko emocji, uczuć, myśli, skojarzeń powstałych pod wpływem obcowania ze sztuką muzyczną. Z jednej strony stymulowany muzyką, z drugiej zaś integrowany z nią i wybranymi jej elementami stanowi zasadniczy środek oddziaływania stosowany w muzykoterapii dzieci.

Słuchana muzyka poprzez swoje elementy strukturalne takie jak: rytm, metrum, tempo, dynamika pobudza wyobraźnię dziecka, sugeruje natężenie i płynność wykonywanych przez niego ruchów, pomaga w zapamiętywaniu kolejności czynności ruchowych ${ }^{19}$. W ten sposób wpływa porządkująco i harmonizująco na jego motorykę, zachęcając je do nieskrępowanego poruszania i przemieszczania się $\mathrm{w}$ przestrzeni oraz wykonywania czynności potrzebnych w codziennym życiu, takich m.in. jak zabiegi toaletowe, przygotowywanie i spożywanie posiłków, słanie łóżka, pranie, prasowanie, składanie ubrań, ubieranie i rozbieranie się ${ }^{20}$.

Wydobywanie przez dziecko odgłosów akustycznych przy pomocy prostych czynności ruchowych określa się mianem muzykowania gestodźwiękami lub muzykowania naturalnego. Niekonwencjonalnymi źródłami dźwięków są wówczas np.: klaszczące dłonie, tupiące nogi, pstrykające palce dziecka. W ten sposób uczy się ono autoorientacji, opanowuje czynności samoobsługowe i lokomocyjne. Ponad to ta odmiana muzykowania jest jednocześnie formą masażu jego ciała.

Małe niewidome dziecko interesuje się różnorodnymi przedmiotami w swoim najbliższym otoczeniu, czyniąc je źródłem różnorodnych zjawisk akustycznych, takich jak np.: piszczenie, dzwonienie, brzęczenie, dudnienie, szumienie, skrzypienie, stukanie i terkotanie. W ten sposób rodzi się muzykowanie na przedmio-

19 A. Pielecki, E. Skrzetuska, Nauczanie niedowidzących w klasach 4-8, WSiP, Warszawa 1991, s. 130.

${ }^{20}$ M.D. Bertolami, L.A. Martino, Music Therapy in a Private School for Visually Impaired and Multiply Handicapped Children, „In Voices: A World Forum for Music Therapy" 2002, t. 2, nr 1, https://voices.no/index.php/voices/article/view/69/59 [dostęp: 24.06.2018]; P. Kern, M. Wolery, Participation of a preschooler with visual impairments on the playground: Effects of musical adaptations and staff development, „Journal of Music therapy" 2001, nr 38(2), s. 149-164. 
tach codziennego użytku (kubkach, butelkach, grzebieniach, celofanie, piszczących maskotkach, klockach, szufladach, kaloryferach itp.), które aktywizuje dziecko, doskonaląc sprawność manualną i słuchową.

Najczęściej stosowanymi instrumentami muzycznymi w pracy $\mathrm{z}$ niepełnosprawnym dzieckiem są proste instrumenty perkusyjne zwane popularnie instrumentami szkolnymi (grzechotki, bębenki, klawesy, kołatki, tamburyna, janczary itp.). ${ }^{21}$. Wśród sposobów pobudzania ich do brzmienia i wibracji można wymienić: uderzanie dłonią, palcami lub pięścią $\mathrm{w}$ instrument, potrząsanie instrumentem trzymanym $\mathrm{w}$ jednej ręce, uderzanie instrumentem o dłoń, łokieć, kolano, uderzanie jedną częścią instrumentu o drugą, pocieranie dłonią po powierzchni instrumentu, pstrykanie palcami w instrument. Dzięki temu można obok rozwijania jego muzykalności usprawniać małą motorykę, głównie zręczność manualną (np. dotykanie, chwytanie, poruszanie, sięganie, ściskanie, wyciąganie rąk), wpływając korzystnie na szybkość, dynamikę, koordynację i dokładność ruchów.

Dzieci $\mathrm{w}$ ramach muzykoterapii mogą przemieszczać się w przestrzeni małej i dużej: chodząc, maszerując, biegając, podskakując, ślizgając, kołysząc się z jednoczesnym przenoszeniem ciężaru ciała z nogi na nogę. W czynnościach tych dostosowują swoje ruchy do tempa, dynamiki, charakteru, nastroju, czasu trwania utworu muzycznego. W ten sposób wyrabia się u nich głównie koordynacja słuchowo-ruchowa, prawidłowa postawa ciała oraz orientacja przestrzenna. Ćwiczenia naturalnych form lokomocji dzięki zintegrowaniu z dźwiękami działają na dziecko odprężająco, łagodzą jego lęk przed pokonywaniem przestrzeni, przeszkód, obrażeniami ciała, wysiłkiem fizycznym, sprzyjając w ten sposób ugruntowywaniu się u niego poczucia bezpieczeństwa ${ }^{22}$.

${ }^{21} \mathrm{~W}$. Olszewska, Ewolucja w muzykoterapii ze szczególnym uwzględnieniem metody Karla Orffa „Postępy Rehabilitacji” 1992, nr 3, s. 63.

${ }^{22} \mathrm{~W}$. Sapp, Somebody's jumping on the floor: incorporating music into orientation and mobility for preschoolers with visual impairments, "Journal of Visual Impairment \& Blindness" 2011, nr 105(10), s. 715. 
Zabawy muzyczno-ruchowe inspirują dziecko do różnych czynności odpowiednio do zachodzących zmian w muzyce, np. tempa, dynamiki, metrum, artykulacji. Zabawy te oparte są najczęściej na prostych sposobach poruszania i przemieszczania się w przestrzeni, naśladownictwie czynności dnia codziennego. Służą one polepszaniu płynności, precyzji i siły jego ruchów. Przy ich pomocy można także eliminować niepokój motoryczny oraz wyciszać natręctwa ruchowe. Rodząca się w ten sposób atmosfera współdziałania i rywalizacji aktywizuje do zabawy nawet dzieci bierne.

Celem improwizacji muzyczno-ruchowej jest ulepszanie wyobraźni dziecka (zwłaszcza czasowo-ruchowo-przestrzennej), spontaniczności ruchów, umiejętności uzewnętrzniania stanów emocjonalnych. W ramach tej techniki mogą one spontanicznie tworzyć pojedyncze ruchy, ich układy, sposoby poruszania i przemieszczania się, wykonywania czynności dnia codziennego, tańczenia do muzyki. Poprzez improwizowany ruch dziecko lepiej eksploruje własne ciało, pełniej akceptuje i świadomie posługuje się nim.

Muzyka, a szczególnie jej elementy składowe, takie jak barwa i dynamika, mogą być zastosowane w nauczaniu i korygowaniu niewidomych dzieci zewnętrznych wyrazów emocji przejawiających się $\mathrm{w}$ mimice twarzy ${ }^{23}$. W tym celu stosuje się ćwiczenia, w których następuje przeniesienie i przetworzenie środków ekspresji muzycznej na środki ekspresji mimicznej. Odtwarzane utwory muzyczne nastrojem i charakterem sugerują przyjmowane przez dziecko ruchy mięśni twarzy.

W muzykoterapii niewidomych i słabowidzących dzieci stosuje się głównie tańce towarzyskie ${ }^{24}$. Skomplikowane pod względem wykonawstwa oraz wydatkowania wysiłku fizycznego elementy

${ }^{23} \mathrm{H}$. Zamęcka, Metody działania muzykoterapeuty w pracy $z$ dziećmi z uszkodzonym wzrokiem, „Szkoła Specjalna” 1985, nr 3, s. 196.

24 Cenną pomocą w nauczaniu dzieci kroków tańców towarzyskich jest metoda Wacława Wróblewskiego wykorzystująca przestrzenne tablice poglądowe opracowane na bazie sześciopunktu pisma Braille'a w 60 krotnym powiększeniu. W. Wróblewski, Taniec Towarzyski w rehabilitacji osób niewidomych, AWF, Poznań 2005. 
(kroki, obroty, ukłony, ruchy rąk, pozycje głowy, sposoby trzymania partnera itp.) modyfikuje i upraszcza się pod kątem specyfiki funkcjonowania dzieci. Mogą one także bez jakichkolwiek reguł improwizować elementy tańców gestem, ruchem lub na instrumentach muzycznych do oryginalnej lub aranżowanej muzyki tanecznej. Taniec (lub jego elementy) ćwiczą u dziecka koordynację ruchów z materiałem dźwiękowo-muzycznym, ich elegancję, precyzję, wyrabiają prawidłową postawę ciała, doskonalą autoorientację, redukują automatyczne ruchy zwane blindyzmami ${ }^{25}$.

\section{Zakończenie}

Dziecko z niepełnosprawnością wzroku ma pełne możliwości przeżywania muzyki i czerpania z niej wielu prozdrowotnych korzyści. Ten rodzaj sztuki poprzez swój terapeutyczny potencjał inspiruje go do spontanicznej aktywności zadaniowej, muzycznej i zabawowej. Wyzwala, porządkuje i modyfikuje jego ruchy i w ten sposób pobudza wyobraźnię ruchowo-przestrzenno-czasową. Dzięki temu zachowania jego stają się w większym stopniu swobodniejsze, a przez to przewidywalne, dające się lepiej kształtować i korygować. Dzięki temu u niewidomego i słabowidzącego dziecka zmniejsza się zahamowanie psychoruchowe oraz polepsza się orientacja i lokomocja w małej i dużej przestrzeni. Prócz tego wykonywanym ruchom niejednokrotnie towarzyszy radość wynikająca z zaspokojenia naturalnej potrzeby ruchu, odreagowywanie napięć psychofizycznych i emocjonalnych oraz sublimowanie agresji.

Tyflomuzykoterapia stanowi skuteczną, efektywną i bezpieczną dla dzieci z niepełnosprawnością wzrokową przestrzeń, w której możliwe jest redukowanie opóźnienia ich rozwoju zdolności motorycznych oraz doskonalenie poszczególnych jego komponentów.

25 J. Kuczyńska-Kwapisz, Spostrzeżenia dotyczące prowadzenia zajęć z młodzieża niewidoma w kole tanecznym, „Szkoła Specjalna” 1979, nr 4, s. 288; A. Mazurkiewicz, Zainteresowania muzyczno-taneczne niewidomych, „Kultura Fizyczna” 1968, R. XXI, nr 3, s. 122. 
Można zaryzykować twierdzenie, iż ruch obok muzyki jest najważniejszym środkiem oddziaływania stosowanym w tego typu oddziaływaniach. Nabywane przez dziecko różnorodne pozytywne doświadczenia związane $\mathrm{z}$ aktywnością ruchową transponowane są z obszaru oddziaływań terapeutycznych na bezwzrokowe funkcjonowanie, przyczyniając się tym samym do podnoszenia jakości jego życia. Z tych to względów można sądzić, iż oddziaływania tyflomuzykoterapeutyczne mogą służyć wspomaganiu rozwoju ruchowego dziecka z niepełnosprawnością wzroku przy jednoczesnym zaangażowaniu zachowanych zmysłów i wykorzystaniu twórczych potencjałów.

\section{Bibliografia}

Antović M., Bennett A., Turner M., Running in circles or moving along lines: Conceptualization of musical elements in sighted and blind children, „Musicae scientiae” 2013, nr 17(2).

Bertolami M.D., Martino L.A., Music Therapy in a Private School for Visually Impaired and Multiply Handicapped Children, „In Voices: A World Forum for Music Therapy" 2002, t. 2, nr 1, https://voices.no/index.php/voices/article/view/69/59 [dostęp: 24.06.2018].

Brambring M., Divergent development of gross motor skills in children who are blind or sighted, "Journal of Visual Impairment \& Blindness" 2006, nr 100(10).

Darrow A.A., Novak J., The effect of vision and hearing loss on listeners' perception of referential meaning in music, "Journal of Music Therapy" 2007, nr 44.

Decker-Voigt H.H., Musiktherapeutische Hilfen für die Begleitung von Blinder und Schbenhinderten, "Musiktherapeutische Umschau” 1994, t. 15, nr 2.

Dziedzic-Szeszuła E., Wprowadzenie, [w:] W. Wróblewski Taniec Towarzyski w rehabilitacji osób niewidomych, AWF, Poznań 2005.

Eitan Z., Ornoy E., Granot R.Y., Listening in the dark: Congenital and early blindness and cross-domain mappings in music, "Psychomusicology” 2012, $\mathrm{nr} 22(1)$.

Emery R., Blind role models in rehabilitation, "Journal of Visual Impairment and Blindness" 1986, nr 80(9).

Flowers P.J., Wang C.H., Matching verbal description to music excerpt: The use of language by blind and sighted children, "Journal of Research in Music Education" 2002, nr 50(3).

Haibach P.S., Wagner M.O., Lieberman L.J., Determinants of gross motor skill performance in children with visual impairments, "Research in developmental disabilities" 2014, nr 35(10). 
Kędzierska J., Planowanie pracy rewalidacyjnej z dziećmi niewidomymi i słabowidzącymi w szkołach ogólnodostępnych, [w:] Dajmy szansę niewidomym i stabowidzącym. Poradnik metodyczny dla nauczycieli, red. T. Żółkowska, „Pedagogium” Wydawnictwo OR TWP w Szczecinie, Szczecin 2010.

Kern P., Wolery M., Participation of a preschooler with visual impairments on the playground: Effects of musical adaptations and staff development, "Journal of Music therapy" 2001, nr 38(2).

Kuczyńska-Kwapisz J., Spostrzeżenia dotyczące prowadzenia zajęć z młodzieża niewidoma w kole tanecznym, "Szkoła Specjalna” 1979, nr 4.

Lam R. C., Wang C., Integrating Blind and Sighted through Music, „Music Educators Journal" 1982, nr 68(8).

Levtzion-Korach O., Tennenbaum A., Schnitzer R., Ornoy A., Early motor development of blind children, "Journal of paediatrics and child health" 2000, nr 36(3).

Malloch S.N., Mothers and infants and communicative musicality, "Musicae scientiae” 1993, nr 1_suppl.

Mazurkiewicz A., Zainteresowania muzyczno-taneczne niewidomych, „Kultura Fizyczna" 1968, R. XXI, nr 3.

Metell M., "A great moment... because of the music": An exploratory study on music therapy and early interaction with children with visual impairment and their sighted caregivers, „British Journal of Visual Impairment” 2015, nr 33(2).

Miedziak A.I., Perski T., Andrews P.P., Donoso L.A., Stargardt's macular dystrophy a patient's perspective, "Optometry” 2000, nr 71(3).

Murphy F.M, O'Driscoll M., Observations on the Motor Development of Visually Impaired Children Interpretations from Video Recordings, "Physiotherapy” 1989, nr 75(9).

Okupińska A., Zagadnienia rehabilitacji i edukacji osób głuchoniewidomych, [w:] Dajmy szanse niewidomym i stabowidzacym. Poradnik metodyczny dla nauczycieli, red. T. Żółkowska, „Pedagogium” Wydawnictwo OR TWP w Szczecinie, Szczecin 2010.

Olszewska W., Ewolucja w muzykoterapii ze szczególnym uwzględnieniem metody Karla Orffa, „Postępy Rehabilitacji” 1992, nr 3, s. 61-68.

Palak Z., Uczniowie niewidomi słabowidzacy w szkołach ogólnodostępnych, Wydawnictwo UMCS, Lublin 2000.

Pavlicevic M., Dynamie interplay in clinical improvisation, „The Journal of British Music Therapy" 1990, t. 4, nr 2.

Pfammatter X., Music as a Leisure-Time Occupation for the Blind, "Review of the European Blind" 1988, nr 2(60).

Pielecki A., Skrzetuska E., Nauczanie niedowidzacych w klasach 4-8, WSiP, Warszawa 1991.

Preisler G.M., A descriptive study of blind children in nurseries with sighted children, „Child: care, health and development" 1993, nr 19(5). 
Sapp W., Somebody's jumping on the floor: incorporating music into orientation and mobility for preschoolers with visual impairments, "Journal of Visual Impairment \& Blindness" 2011, nr 105(10).

Sobey K., Out of sight - out of mind?, Reflections on a blind young woman's use of music therapy, „The Journal of British Music Therapy” 1999, t. 7, nr 2.

Stadnicka J., Rewalidacja dzieci niewidomych przez rytmike, "Szkoła Specjalna" 1990, nr 2-3.

Steele A.L., Crawford C., Music Therapy for the Visually Impaired, „Education of the Visually Handicapped" 1982, nr 14(2).

Tröster H., Brambring M., Early motor development in blind infants, "Journal of applied developmental psychology" 1993, nr 14(1).

Wolf F. M., Music Therapy with the Blind, "British Journal of Music Therapy" 1978, nr 9(3).

Wróblewski W., Taniec Towarzyski w rehabilitacji osób niewidomych, AWF, Poznań 2005.

Wypart R., Praca nauczyciela wychowania fizycznego z uczniem $z$ dysfunkcja wzroku, [w:] Dajmy szansę niewidomym i stabowidzacym. Poradnik metodyczny dla nauczycieli, red. Żótkowska Teresa, „Pedagogium” Wydawnictwo OR TWP w Szczecinie, Szczecin 2010.

Zamęcka H., Metody działania muzykoterapeuty w pracy z dziećmi z uszkodzonym wzrokiem, „Szkoła Specjalna” 1985, nr 3. 